view that nitrate is converted to nitrite and hydroxylamine, and there is evidence that the step from nitrate to nitrite is relatively slow. The synthesis of amino-acids and amides is closely associated with high rates of respiration and rapid losses of carbohydrates from the tissues. Evidence is presented that both the carbon skeleton of the amides and the respiratory carbon dioxide result from the breakdown of carbohydrate. 'The regulatory mechanisms which may operate during the assimilation of different forms of nitrogen are discussed. No marked inerease of tissue proteins occurs in the excised roots ; but an extensive incorporation of nitrogen-15 into these proteins could be detected. There is no evidence that the operation of a continuous protein cycle plays an important part in regulating the rate of respiration in these roots.

\section{Zoological Nomenclature}

THE International Commission on Zoological Nomenclature will start voting as from March 28, 1957, on the following cases involving the possible use of its plenary powers ; full details have already been published (Bull. Zoo. Nom., 12, Pt. 9 ; September 1956): (1) Rafinesque, 1814-1818, names published by, for genera and species in the orders Decapoda and Stomatopoda (cl. Crustacea), suppression; (2) cruentatus Linnaeus, 1758, cubicus Forskål, 1775, and novemdecos Sulzer, 1776, all published in combination with the generic name Cancer (cl. Crustacea, order Decapoda), suppression ; (3) Urinatoridae Vieillot, 1818, suppression of, in favour of Gaviidae Coues, 1903 (cl. Aves); (4) Peltura (omend. of Peltoura) Milne Edwards (H.), 1840 (cl. 'Trilobita), validation. Comments should be sent as soon as possible to Francis Hemming, 28 Park Village East, Regent's Park, London, N.W.1.

\section{Insecticidal Effect of Nigerian Diatomite}

Comparative tests have been made by E. A. Parkin and Enid I. C. Scott, of the Pest Infestation Laboratory of the Department of Scientific and Industrial Research, and E. R. Varley, of the Mineral Pesources Division of the Colonial Geological Surveys, on the insecticidal efficiency of a colloidal silica preparation and several particle-size fractions of a Nigerian diatomite to assess the potentiality of the latter for local use in the protection of infestable stored produce (Col. Plant and Animal Prod., 5, No. 3 ; 1956). The tests were made with Calandra granaria, $C$. oryzae and Tribolium castaneum. The finest fraction of the diatomite had a good insecticidal effect at $25^{\circ} \mathrm{C}$. and 70 per cent relative humidity when used as a dry dust, although it was not so effective as the colloidal silica. However, when applied as an aqueous suspension to bricks, the dry deposit of colloidal silica was insecticidally efficient, whereas that of the diatomite failed completely because of caking. It would have been particularly advantageous in the groundnut storage areas of Northern Nigeria if the diatomite could have been used in aqueous suspension to avoid excessive losses during application of dry dusts in the local high winds.

\section{Electron Physics Tables}

Tre National Bureau of Standards, Washington, D.C., has recently prepared "Electron Physics Tables" (Circular No. 571; pp. 83. Washington : Government Printing Office, 1956 ; 50 cents), which replace the out-of-print and partly obsolete tables published in 1941 as Part 2 of "Miscellaneous Physical 'Tables. Planck's Radiation Functions and Electron Functions. U.S. National Bureau of Standards. Mathematical Tables 17". The calculation of the tables was carried out on the Bureau's automatic digital computer, SEAC, and the eight tabulated quantities, each given to eight significant figures, are: the potential difference in absolute volts required to impart a kinetic energy $E$ expressed in electron volts to an electron initially at rest; the effective relativistic potential difference; the product of magnetic field strength in cersteds and the radius of curvature of electron path in centimetres ; the de Broglie wave-length of the electron; the momentum of the electron measured in units of $m_{0} c$, where $m_{0}$ is the rest mass of the electron and $c$ is the velocity of light; the kinetic energy of the electron measured in units of its rest mass energy, $m_{0} c^{2}$; the total energy of the electron measured in units of the rest energy ; and the ratio of the electron velocity to the velocity of light. The electron energies quoted range from $0 \cdot 206 \mathrm{eV}$. to $3 \cdot 353 \times 10^{12} \mathrm{eV}$. The values of the fundamental constants adopted in the computation of the tables are those given by J.W. M. Dumond and TE. R. Cohen (Rev. Mod. Phys., 25, 69l; 1953).

\section{Photometric Theory of Lunar Eclipses}

THE sixteen lunar eclipses between October 16 , 1921 , and July 15, 1954, are discussed by F. Link in a paper, written in Czech but with an English summary, entitled "Catalogue of Eclipses of the Moon, 1921-1954. 2: Measurements of the Density of the Shadow" (Pub. C 29, Nak. Čsk. Akad. Věd, Praha; 1956). In 1933, Link had established a photometric theory of lunar eclipses, based on contemporary knowledge of the terrestrial atmosphere and directed specially to the exploration of the upper atmosphere (C.R. Acad. Sci., Paris, 196, 251 (1933), and Bull. Astron., 8, $77(1933))$. Since then the numerical results of his theory have served for comparison with measurements of the density of the Earth's shadow, and the object of the present paper is to give a summary of these comparisons in view of a proposed revision of the earlier theory. Many precautions are necessary in measuring the density of the terrestrial shadow thrown on the Moon, and certain disturbing factors intervene-in particular, the light scattered in the instrument used for tho measurements or in the Earth's atmosphere, and then the atmospheric absorption and its variations, which are all likely to vitiate considerably the measurements. Fortunately, the photometer described by A. Danjon (Ann. Obs. Strasbourg, 2,$1 ; 1928$ ) provides results in which systematic errors are automatically eliminated. There is now a long series of measurements of this nature which were made between 1921 and 1954, and the work under consideration contains the results of this series. In addition to sixteen pages of tabular matter showing the densities of the shadows, there are sixteen curves--one for each eclipseshowing the densities as functions of the angular distance from the centre of the shadow, and other curves and diagrams supplying additional information. A detailed discussion has been reserved for the future, but the following provisional deductions have been made. In the shadow and in the green and red parts of the spectrum, there is normally a deficiency of light with regard to the Rayleigh atmosphere, but in tho blue-and in exceptional circumstances in the green and red-there is an excess of light with 